\title{
Historical Regional Demographic Divergence in Latvia: Lessons of the Common Past with Eastern Partnership Countries
}

\author{
Aleksandrs Dahs \\ Centre for European and Transition Studies, \\ University of Latvia \\ Kalpaka blvd. 4, \\ Riga LV-1586, Latvia \\ E-mail: Aleksandrs.Dahs@lu.Iv
}

\begin{abstract}
In recent decades, scientific literature on demographic research is increasing attention on spatial data analysis. It is considered a useful and reliable analysis methodology in evaluating complex regional development processes. However, due to its complexity and reliance on properly captured and quantified spatial relations, it remains a difficult topic for many scholars and practitioners. In Latvia, spatial demographic analysis may prove useful, providing opportunities for uncovering new dimensions of long-term regional demographic and economic development issues. Here, the author analyses spatial distribution aspects of key demographic indicators in Latvia's municipalities, the associated socio-economic factors and their impact. The implications of the identified spatial processes and dependencies for regional development policy and aid are discussed, including possible lessons learned from or shared with the EU Eastern Partnership countries facing similar challenges.
\end{abstract}

Keywords: exploratory data analysis, regional demographic convergence, regional development, spatial econometric analysis, time-series clustering 


\section{Introduction}

It can be easily seen from the previous studies and official reports (e.g., SRDA, 2012) that on the level of individual local municipalities, Latvia, as well as many other European countries, face significant challenges of spatial divergence in terms of social, economic and demographic development.

Brainerd (2009) argues that while such and other demographic problems in the Western European countries are a result of long-term social, economic and natural processes, the formerly socialist countries of Eastern Europe and the former Soviet Union are relatively new to these issues, as they have experienced a remarkable demographic transformation during just the past twenty years. In terms of population development, this is a relatively short period, which means that the underlying strengths and weaknesses of the national and regional demographic development in many new EU Member States, including Latvia, share more similarities with those of the Eastern Partnership countries, rather than with Western Europe.

In their book, From Red to Gray: The "Third Transition" of Aging Populations in Eastern Europe and the Former Soviet Union, Chawla and others (2007) explain that the Eastern European countries have not just undergone a political, social and economic transition, but also have fast-tracked through the demographic transition, which was different from the one being experienced by the wealthier aging countries of Western Europe. This, in turn, raises concerns that the impact of aging populations will undermine the long-term success of the socio-economic transitions by putting economic growth and social sustainability at risk. The 2008-2010 economic crisis experienced in Latvia shows that such threat is even more evident on the regional level, where rapidly reduced population potential and changing population age structure are unable to accommodate the demands of modern economy.

From the available statistical data (e.g., SRDA, 2013) it is also possible to observe that different regions demonstrate very different trends of population development, which not only correlate with the social and economic progress of the particular region, but are also to a large extent determined by its geographical location within the country.

Over the last few decades, there has been growing interest in research concerning both spatial and temporal aspects of complex socio-economic and demographic regional processes. Quantitative analysis of the development processes, employing specialised methods and models, facilitates deeper understanding of 
the spatial distribution of the indicators under study, and often allows discovering new and previously unseen dimensions of deep regional development problems.

Therefore, this study aims to analyse the spatial aspects of several key demographic indicators of Latvia's municipalities, while attempting to identify the associated socio-economic factors and spatial effects. For this purpose, the author conducted a spatial econometric analysis of Latvian municipalities' data using time-series clustering and spatial autocorrelation analysis, while drawing parallels with some of the EU Eastern Partnership countries and other postSoviet states in order to understand the uncovered situation and explore possible solutions and best practices.

Such analysis, combined with the extensive review of theoretical materials and historical information, leads to several conclusions regarding spatial specifics of regional demographic development in Latvia. These include a formation of distinct groups (clusters) of municipalities with similar historical population development paths and stable spatial relationships, along with the noticeable long-term divergence of demographic development trends between these groups, as well as the presence of spatial spill-over effects between municipalities, both in terms of economic and demographic development.

\section{Administrative-territorial reforms and historical population data}

First, in order to conduct any form of spatial demographic analysis aimed at identifying the long-term trends, as well as having a reliable and, most importantly, comparable results, one needs to obtain historical data, which would fit within a single frame of reference. In the case of Latvia, the historical population census results from the period after World War II may be used for such a purpose. Census years in this period include 1959, 1970, 1979, 1989, 2000 , and 2011. However, due to the numerous territorial rearrangements over the period in question, these data cannot be compared in the initial form and need to be recalculated.

In Latvia, in the period since 1959, several significant administrative rearrangements were conducted during both the period of Soviet occupation and the following years of independence. Between general population censuses of the Soviet republics of 1959 and 1970, the 649 level two local administrative units (LAU2), known as Rural Councils and Cities were gradually reorganised into 539 Parishes and Cities. According to previous research, this number was 
further reduced to 465 LAU2 by the census of 1989 (Skinkis, 1999, p. 69). Ramute (2008, p. 36) explains that both models and functions of administrative units have changed since Latvia regained independence in 1991. A new socioeconomic formation of the country demanded further changes in the regional structure and policy that resulted in the introduction of an administrativeterritorial reform, which was envisaged in 1998, gradually carried out in the period from 1999 to 2009, and resulted in a completely new single-level system of local administrative units with only 119 LAUs: 110 local municipalities, or novadi, and 9 republic cities.

Such noticeable changes in administrative division over a relatively short time period makes it nearly impossible to conduct any form of statistical, econometric or exploratory analysis of the historical spatial distribution and long-term development trends of population, and therefore, underlines the necessity to perform the recalculation, or at least, an estimation, of the historical population figures in accordance with single (preferably contemporary) spatial framework.

Due to the lack of precise cartographic information and the scale of territorial rearrangements in Latvia, a custom method has been developed and applied, which uses population census data along with the available archive information in the form of documents and maps (if available), in order to trace the changes in the boundaries and names of the territorial units and perform the necessary recalculations. This recalculation has been conducted within the framework of DG REGIO 2012 tender "Population Data Collection For European Local Administrative Units From 1960 Onwards" undertaken by Spatial Foresight $\mathrm{GmbH}$. The recalculated population data for Latvia and many other EU Member States are being circulated within the ESPON community. Furthermore, a publication on the Eurostat website is foreseen in late 2014.

With the double purpose of capturing the population development in the individual municipalities as the dynamic process, as well as making the data more comparable between the municipalities of different size, population growth rates for each observed territorial unit are calculated for every time interval between the populations censuses (see Table 1). Such approach also makes it possible to analyse the spatial population dynamics in both temporal and spatial cross-sections. 
Table 1. Preview of the population dynamics in the territories of modern Latvian municipalities between the censuses of 1959-2011, based on recalculated data.

\begin{tabular}{|l|c|c|c|c|c|}
\hline \multirow{2}{*}{ Municipality } & \multicolumn{5}{|c|}{ Population growth rate } \\
\cline { 2 - 6 } & $\begin{array}{c}1959- \\
1970\end{array}$ & $\begin{array}{c}1970- \\
1979\end{array}$ & $\begin{array}{c}1979- \\
1989\end{array}$ & $\begin{array}{c}1989- \\
2000\end{array}$ & $\begin{array}{c}2000- \\
2011\end{array}$ \\
\hline Aglonas novads & -0.215 & -0.120 & -0.152 & -0.163 & -0.283 \\
\hline Aizkraukles novads & 3.673 & 0.344 & 0.390 & -0.076 & -0.138 \\
\hline Aknīstes novads & -0.074 & -0.111 & -0.135 & 0.039 & -0.217 \\
\hline Alojas novads & 0.014 & -0.031 & -0.067 & -0.029 & -0.257 \\
\hline Alsungas novads & 0.219 & -0.170 & -0.037 & -0.052 & -0.292 \\
\hline Amatas novads & -0.133 & -0.125 & -0.070 & 0.026 & -0.186 \\
\hline$\ldots$ & $\ldots$ & $\ldots$ & $\ldots$ & $\ldots$ & $\ldots$ \\
\hline $\begin{array}{l}\text { Total population } \\
\text { change: }\end{array}$ & 0.131 & 0.064 & 0.065 & -0.108 & -0.129 \\
\hline
\end{tabular}

Source: Author's calculations based on historical census data provided by the Central Statistics Bureau of Latvia (CSB, n.d.)

As was previously indicated, in the following sections the author conducts a spatial exploratory analysis of the adjusted historical population data of the Latvian municipalities using a wide range of research tools, including clustering analysis and spatial autocorrelation analysis as suggested in the literature (Voss et al., 2006).

\section{Capturing the divergence of historical population trends}

In order to better understand the existing regional demographic divergence in a long-term perspective, it is extremely useful to understand whether there are some distinctive types of territories present with similar development trends within and divergent trends between them. The right analytical tool for this purpose would undoubtedly be the clustering.

Warren Liao (2005) explains that the goal of clustering is to identify structure in a data set by objectively organising data into homogeneous groups where the within-group-object similarity is minimised and the between-group-object dissimilarity is maximised. Clustering is useful regardless of whether the data are binary, categorical, numerical, interval, ordinal, relational, textual, spatial, 
temporal, spatio-temporal, image, multimedia, or mixtures of the above data types. The bulk of widely used and discussed clustering methods may be easily applied to static data.

The historical population trends under study, however, are not static, and in fact, represent a dynamic time-series that significantly complicates and limits their clustering possibilities. Unlike static data, the time series comprise values changing with time. Similarly to static data clustering, time-series clustering requires an algorithm or procedure to form clusters from a given set of data objects. The choice of the most suitable clustering algorithm depends both on the type of data available and on the particular purpose of the study.

As it can be seen from the available methodology reviews, a wide variety of algorithms have been developed to cluster different types of time-series data (see Liao, 2005). The majority of them, however, try to use the existing static algorithms, while converting the time-series data into the form of static data by obtaining some specific and static measure of similarity between the time series (e.g., correlation measures, fitted model parameters, etc.).

For the purpose of this study, an agglomerative hierarchical clustering method has been chosen. Such a method works by grouping data objects into a tree of clusters, starting by placing each object in its own cluster and then merging clusters into larger and larger groups, until all objects are in a single cluster or until certain termination conditions, such as the desired number of clusters, are satisfied. For the measure of similarity, a simple correlation coefficient is used for capturing individual similarity/dissimilarity for every permutation of observations in form of a simple square $(\mathrm{n}=119)$ correlation matrix (see Fig. 1).

In order to better suit the hierarchical clustering algorithm, and taking into consideration the positive and negative values of the correlation coefficient, the correlation matrix has been changed into the distance matrix via transformation

$$
\text { Dist }_{i j}=1-\text { correlation }_{i j}, \quad i, j=(\overline{1, n})
$$

The resulting distance matrix may then be used as a basis for agglomerative hierarchical clustering process, the results of which are best presented in the form of a dendrogram (tree-chart) as shown in Figure 2. At this point the main problem is a choice of the clustering or "cut-off" distance, which would define the number and structure of individual clusters. Kavitha and Punithavalli (2010) report that the available scientific literature does not provide a single solution for this issue. It is therefore acceptable to choose this distance on the basis of the desired number of clusters and researchers knowledge of the data at hand. 
Figure 1. Correlation matrix graph of the population dynamics in modern Latvian municipalities between population censuses of 1959-2011. *

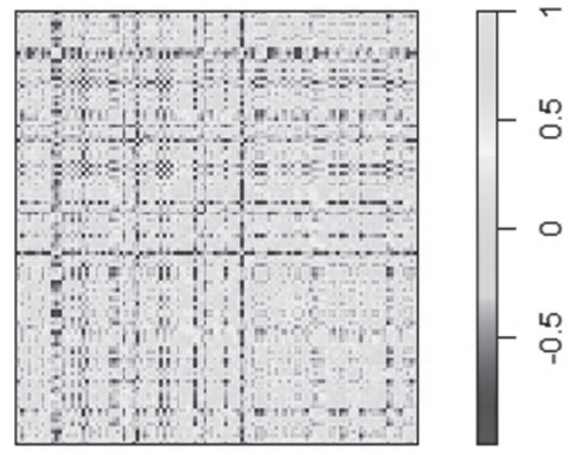

Source: Author's elaboration

With this in mind, the cut-off distance of 1.25 is chosen for the purpose of this study, as it provides the acceptable number of clusters $(k=7)$ and captures known, historically similar municipalities (e.g., Iecavas, Ādažu and Ķekevas) in a separate group, while avoiding unnecessary splitting of the more homogenous groupings.

After the clustering process is complete, it is useful to understand the nature of divergence between the clusters. In our case, simple average values of the population growth rates of the municipalities within the identified clusters (as shown in Table 2) are sufficient to help one understand the general historical population growth rate tendencies within the identified homogenous groups.

An interesting tendency may now be observed: those groups of municipalities (Clusters 2, $6 \& 7$ ) which had an unnaturally high population growth during one or both of the first two observed time intervals, on average, show better results during the entire 1959-2011 period, and, most importantly, are demonstrating far better comparative results even in modern times (2000-2011 interval).

* Figure 1 is available in high resolution at http://www.ies.ee/bjes/Dahs-Fig1.pdf 
Figure 2. Dendrogram showing hierarchical clustering of modern Latvian municipalities by their historic population trends in 1959-2011. *

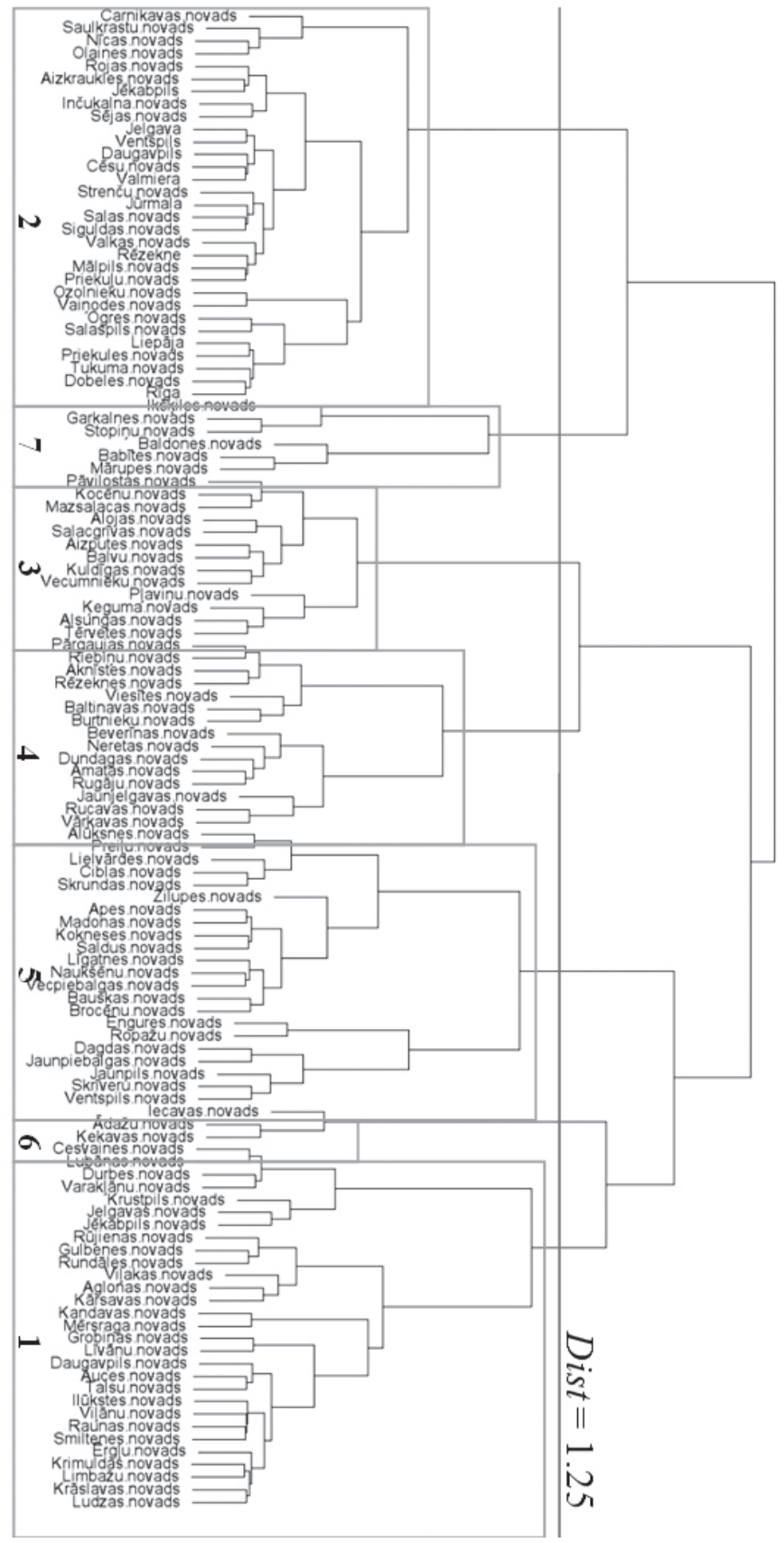

Source: Author's elaboration

* Figure 2 is available in high resolution at http://www.ies.ee/bjes/Dahs-Fig2.pdf 
Table 2. Comparison of the average population growth rates within the identified clusters.

\begin{tabular}{|c|c|c|c|c|c|}
\hline \multirow{2}{*}{ Cluster } & \multicolumn{5}{|c|}{ Population growth rate } \\
\cline { 2 - 6 } & $\mathbf{1 9 5 9 - 1 9 7 0}$ & $\mathbf{1 9 7 0 - 1 9 7 9}$ & $\mathbf{1 9 7 9 - 1 9 8 9}$ & $\mathbf{1 9 8 9 - 2 0 0 0}$ & $\mathbf{2 0 0 0 - 2 0 1 1}$ \\
\hline $\mathbf{1}$ & -0.151 & -0.042 & -0.026 & -0.069 & -0.207 \\
\hline $\mathbf{2}$ & 0.582 & 0.147 & 0.109 & -0.104 & -0.085 \\
\hline $\mathbf{3}$ & 0.073 & -0.078 & -0.026 & -0.027 & -0.201 \\
\hline $\mathbf{4}$ & -0.148 & -0.159 & -0.102 & -0.019 & -0.210 \\
\hline $\mathbf{5}$ & -0.009 & -0.052 & 0.096 & -0.087 & -0.170 \\
\hline $\mathbf{6}$ & -0.026 & 0.619 & 0.220 & -0.072 & 0.255 \\
\hline $\mathbf{7}$ & 0.973 & -0.083 & 0.118 & 0.006 & 0.580 \\
\hline
\end{tabular}

Source: Author's calculations based on historical census data provided by the Central Statistics Bureau of Latvia (CSB, n.d.)

This tendency may be generally explained by the politically driven and mostly externally-funded urbanisation and industrialisation processes of the 19591979 period, which fostered an exponential development of economic and social infrastructure only in specific rural areas, regional centres and cities (Cluster 2), and resulted in the creation of the territory (Clusters $6 \& 7$ ) now often referred to in the official publications as Riga area of influence (see SRDA, 2013). Despite losing much of its industrial potential during the transition period of $1990 \mathrm{~s}$, this area became a popular place of residence with high population growth, given that, due to the well-established transport and housing infrastructure, it facilitates classic push-pull migration flows as described by Dorigo and Tobler (1983) and high intensity exchange of services with the national capital city.

On the other hand, in the most rural areas that are remote from republican cities and/or national development centres (Clusters 1, 3, 4 \& 5), a continuous depopulation tendency with only short comparative improvements during the pre-transition period of 1979-1989 and/or the transition period of 1989-2000 may be identified.

These observations also suggest a particular importance of the pre-existing infrastructure, as well as direct access to the long-established regional/national economic and social centres as defining population development factors of the modern Latvian municipalities. Such an assumption may be safely transferred to most of the Eastern Partnership countries and Russia, as these share the common history of Soviet-governed urban and rural development with Latvia. 
It may also be concluded that, unlike in Western European states, in these countries' the groups of municipalities currently showing similar population dynamics may have divergent historical trends leading to the current situation. Therefore, from the population development perspective, these countries' groups of municipalities have different underlying strengths and weaknesses in terms of available infrastructure, reproduction potential and migration behaviour. This also means that different long-term reactions to the various policy instruments and regional aid measures should be expected from the different groups of apparently similar regions.

Finally, it is also possible to notice that the general long-term tendencies of the population dynamics of the identified clusters are following the similar development trends over the whole period under investigation despite the economic, social and political changes. In other terms, groups of territories with similar initial development trends do not tend to converge, but rather continue to diverge over the course of time. This observation seems to at least partly support the assumption on the constant nature of the regional demographic development trends in the former Soviet countries (including Latvia and Eastern Partnership countries) in the long time periods, as it has been theorised in the literature (see Golc, 2004).

\section{Long-term spatial associations}

While the cluster analysis, described in the previous section of this article, provides valuable insight in the temporal and structural dimensions of regional population development, understanding the underlying spatial associations is just as important in order to see the full picture of regional population dynamics. The classical approach towards measuring and visualising spatial association is based on the concept of Moran's I statistic and the associated Moran scatter plot.

Anselin (1999) explains that Moran's I statistic for spatial autocorrelation can be defined as a regression coefficient in a bivariate spatial lag scatter plot, that is, in a scatter plot with the spatial lag on the vertical axis and the value at each location on the horizontal axis. In this case Moran's I calculated value corresponds to the slope of the regression line through the points. Closer study of this particular methodology indicates that this allows for a simultaneous assessment of both global (the slope of the line) and local spatial association (local trends/clusters in the scatter plot). The further evaluation of these local associations is done by the decomposition of scatter area into four quadrants, each representing different type of spatial association. 
For the purpose of such analysis, a simple square $(n=119)$ spatial weights matrix was created, containing the inverse values of geometric distances between the geographical coordinates of the centre points of 119 of Latvia's local municipalities and republican cities. Therefore, this matrix captures the municipalities' and republican cities' approximate neighbourhood structure required for calculating the spatially lagged values, which, in turn, are at the basis of the Moran's I concept.

Using the developed simple spatial weights matrix together with the available population dynamics data, it is now possible to conduct a series of Moran's I spatial autocorrelation tests and construct the corresponding scatter plots for the previously calculated historical population growth figures in the given time intervals (Fig. 3).

The analysis of the Moran's I test statistic allows one to reject the null-hypothesis of zero-autocorrelation for all of the observed periods with a high degree of certainty, which indicates that a noticeable level of spatial autocorrelation in terms of population growth is present between the territories of modern Latvian municipalities in all five time intervals under study.

Figure 3. Moran scatter plots showing spatial autocorrelation tendencies in modern Latvian municipalities in 1959-2011 period. *

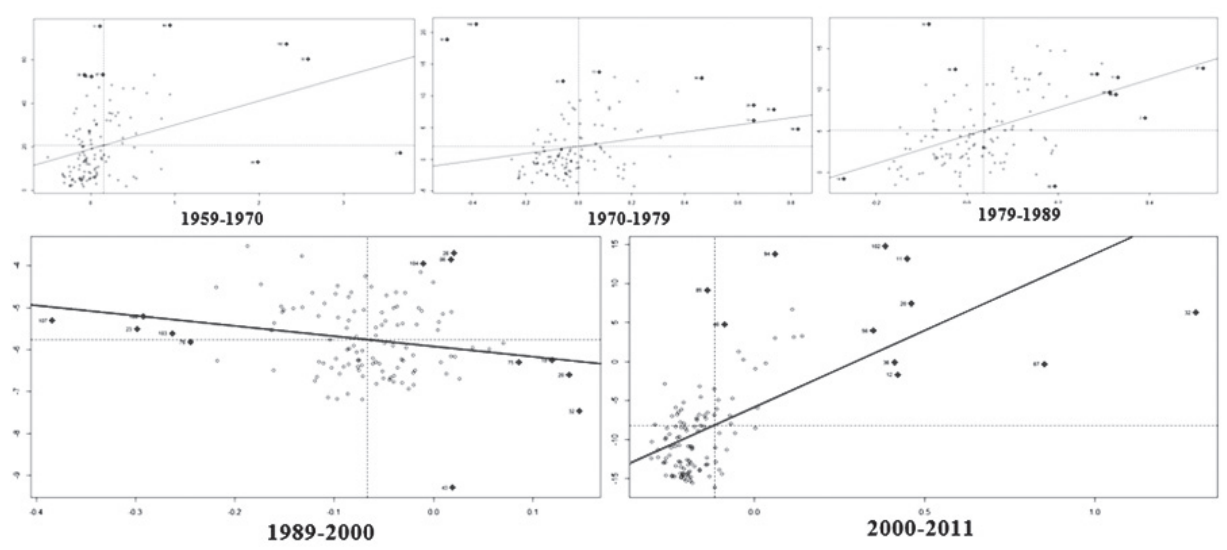

Source: Author's elaboration

* Figure 3 is available in high resolution at http://www.ies.ee/bjes/Dahs-Fig3.pdf 
It is interesting to note, however, that during the transition period (1989-2000), Moran's I statistic value is negative, which can clearly be seen from the associated scatter plot. This means, that in all of the observed periods, territories with comparatively higher population growth rates were spatially close to each other, with the exception of 1989-2000 time interval, when the situation was reversed.

Closer study of individual measurements presented on the scatter plots generally confirms the results obtained from the clustering process described above. As in almost all cases, territories belonging to one of the identified clusters are occupying the same quadrant of the Moran scatter plot diagram. In addition, the trend-setter units (extremes) in 1959-1989 and 2000-2011 scatter plots normally belong to Clusters 2, 6 and/or 7 .

In many aspects, the 1959-1970 and 2000-2011 scatter plots are the most similar, both having nearly empty third quadrant (high growth and low spatial lag), which indicates that in these cases there is a noticeable tendency towards urbanisation and concentration of population inhabiting rural areas. While the causes of such a dynamic in 1959-1970 may be easily explained by rural collectivisation and influx of foreign labour force into cities and urban areas, the 2000-2011 period presents a much more complex picture.

However, the fact that in both cases the trend is defined by the same groups of territories (Clusters 2, 6 and 7), one may theorise the presence of similar spatial demographic processes influenced by the (once again) growing role of cities and development centres as focal points of economic and social activity.

This conclusion brings important implications for the existing and future population development programmes. Among other cases, it may partially explain the inconclusive results of the "demographic security" programmes implemented in Russia and Belarus, where governments are providing additional economic stimuli in the form of financial support and/or tax reliefs for the families with more than one/two children, which resulted in even greater population growth in the big cities and apparently did not affect rural depopulation processes (see, e.g., FSSS, 2014).

The unusual negative Moran's I statistic value and the underlying rural population increase during the transition period of 1989-2000 requires additional attention, as it was most likely linked with the whole set of economic, social and political processes present after the restoration of independence and widely discussed in the literature (see The World Bank, 1993). This fact requires closer evaluation in further studies focusing on the population development in Latvia, as well as in other Eastern European states, Eastern Partnership countries and Russia. 


\section{Conclusions}

First, it is necessary to stress that in long-term spatio-temporal population research in the former Soviet states, it is both possible and useful to conduct a recalculation of the available historical data in accordance with the single and, preferably, modern frame of reference even in the countries/regions with significant rearrangements in their administrative division caused by political or socio-economic transitions.

Second, the spatial econometric analysis indicates that those clusters of municipalities which had an unnaturally high population growth during the 1959-1979 period, on average, show better results during the entire 1959-2011 period, and, most importantly, are demonstrating far better comparative results even in modern times (2000-2011).

Such situation may be explained by the fact that urbanisation and industrialisation processes present after World War II in the Soviet bloc countries fostered an exponential development of economic and social infrastructure only in specific rural areas, regional centres and cities, and has created significant territories of influence around national capital cities and industrial centres.

Third, these observations, in combination with spatial associations analysis, underline a particular importance of the pre-existing infrastructure and direct access to the long-established regional/national economic and social centres as defining population development factors even in the modern times.

Finally, and most importantly, it may also be concluded from the Latvian example that those territories currently showing similar population dynamics may have arrived to the present situation by the divergent historical trends. Therefore, from the population development perspective, those territories may have different underlying strengths and weaknesses in terms of available infrastructure, reproduction potential and migration behaviour. This also means that different long-term reactions to the various policy instruments and regional aid measures should be expected from the different clusters of apparently similar contemporary regions. 
Aleksandrs Dahs is currently a researcher at the Centre for European and Transition Studies (CETS) and a Ph.D. student at the Demography doctoral study programme at the University of Latvia. He is actively engaged in research activities related to the national and EU Regional and Cohesion policies as well as regional population change and development. In this role, he has been involved in a series of research projects and evaluations conducted by CETS and its partners in cooperation with national and EU public institutions (incl. DG REGIO, EIB, EP). Having academic background in Business Administration and Econometrics, Aleksandrs has developed a very practical and evidence-oriented approach in his research activities. Aleksandrs Dahs has been a member of Latvian Association of Econometrists and the European Association for Population Studies since 2013.

\section{References}

Anselin, L. (1999), 'Interactive Techniques and Exploratory Spatial Data Analysis,' in P.A. Longley, M. F. Goodchild, D. J. Maguire \& D. W. Rhind (eds.) Geographical Information Systems: Principles, Techniques, Management and Applications, Cambridge: Geoinformation Int., pp. 253-266.

Berze, D. (1997), Okupētās Latvijas administratīvi teritoriālais iedalījums [in Latvian], Riga: National Archive Directorate.

Brainerd, E. (2010), The Demographic Transformation of Post-Socialist Countries, Working paper, no. 15, The World Institute for Development Economics Research.

Chawla, M.; Betcherman, G.; Banerji, A.; Bakilana, A.; Feher, C.; Mertaugh, M.; Puerta, M. L.; Schwartz, A. M.; Sondergaard, L. \& Burns, A. (2007), From Red to Gray: The "Third Transition" of Aging Populations in Eastern Europe and the former Soviet Union, Washington DC: The World Bank. http://dx.doi. org/10.1596/978-0-8213-7129-9

CSB (n.d.), Central Statistics Bureau of Latvia database. Retrieved from http://dati.csb.gov.lv [accessed 30 Jan 2014]

Dorigo, G. \& Tobler, W. (1983), 'Push-Pull Migration Laws,' Annals of the Association of American Geographers, vol. 73, no 1, pp. 1-17.

http://dx.doi.org/10.1111/j.1467-8306.1983.tb01392.x

FSSS (2014), Federal State Statistics Service of the Russian Federation population database. Retrieved from http://www.gks.ru [accessed 15 Feb 2014]

Golc, G. A. (2004), 'Dolgovremennye istoricheskie trendy kak faktor ekonomicheskogo prognozirovaniia: transport, ekonomika, demografiia,' [in Russian] Problemy prognozirovaniia, vol. 2, pp. 25-35.

Kavitha, V. \& Punithavalli, M. (2010), 'Clustering Time Series Data Stream - A Literature Survey,' International Journal of Computer Science 
and Information Security, vol. 8, no. 1, pp. 289-294. Retrieved from http://arxiv.org/abs/1005.4270v1 [accessed 17 Feb 2014]

Liao, T. W. (2005), 'Clustering of Time Series Data-a Survey,' Pattern Recognition, vol. 38, no. 11, pp. 1857-1874.

http://dx.doi.org/10.1016/j.patcog.2005.01.025

MPIDR (2011), Project Population History GIS Collection, Project materials, Rostock: Max Planck Institute for Demographic Research. Retrieved from http:/www. demogr.mpg.de/en/laboratories/historical_demography_892/projects/population_ history_gis_collection_1556.htm [accessed 10 Feb 2014]

Ramute, L. (2008), The Analysis and Optimisation of the Administrative-Territorial Division of Latvia, $\mathrm{PhD}$ thesis, Latvia University of Agriculture.

Skinkis, P. (1999), Territories and Territorial Strategies in Latvia, PhD thesis, University of Latvia.

SRDA (2012), Development of Regions in Latvia 2011, State Regional Development Agency Official Report, Riga: VRAA. Retrieved from http://www.vraa.gov.lv/uploads/regionu parskats/Regionu attistiba Latvija 2011 ENG_Q_ia kartes horizontali.pdf [accessed 1 Feb 2014]

(2013), Attīstības centru ietekmes areālu noteikšana un analīze. Plānošanas reǵionu, republikas pilsētu un novadu pašvaldību attīstības raksturojums, [in Latvian] State Regional Development Agency Official Report, Riga: VRAA. Retrieved from http:/www.vraa.gov.lv/uploads/documents/petnieciba/petijumi/ regionu_attist_final_2012.pdf [accessed 1 Feb 2014]

Voss, P. R.; White, K. J. C. \& Hammer, R. B. (2006), 'Explorations in spatial demography,' in W. Kandel \& D. L. Brown (eds.) Population Change and Rural Society, Dordrecht: Springer, pp. 407-429. http://dx.doi.org/10.1007/1-40203902-6_19

The World Bank (1993), Latvia - the Transition to a Market Economy, A World Bank Country Study Series, Washington D.C: The World Bank Publications. 